Bangladesh J. Bot. 49(3): 625-632, 2020 (September)

\title{
EFFECTS OF DIFFERENT LEVELS OF NaCI ON THE SEED GERMINATION OF CYAMOPSIS TETRAGONOLOBA L.
}

\author{
Muhammad Akram, Mehwish Zahid, Abu Bakr Umer Farooq*, \\ Muhammad Nafees ${ }^{1}$ and Atta Rasool \\ Department of Environmental Sciences, COMSATS University Islamabad, \\ Vehari Campus 61100, Pakistan
}

Keywords: Cluster bean, Cyamopsis tetragonoloba, $\mathrm{NaCl}$ salinity, Seed vigour index

\begin{abstract}
Effects of four different levels of $\mathrm{NaCl}(05,10,15,20 \mathrm{dS} / \mathrm{m})$ on the seed germination of cluster bean (Cyamopsis tetragonoloba L.) cultivars were investigated. Only distilled water was used in the control. The experiment was conducted in the Petri dishes under laboratory condition and laid out in CRD comprising five replicates. The results indicated that the germination index (GI), seed vigor index (SVI), germination stress index and seedling length (radicle and plumule) decreased with increase of salinity levels and germination percentage (GP) was reduced significantly at the highest level of salinity (200 $\mathrm{mM})$. However, mean germination time (MGT) and time taken for 50\% germination (T50) increased by increasing salinity levels. Correlation coefficient between all possible combinations was estimated and the results indicated that GP, GI, MGT, T50, and SVI had significant positive or negative correlation with each other.
\end{abstract}

\section{Introduction}

Salinity is one of the major environmental stresses that decrease the crop production particularly, in the arid and semi-arid areas of the world (Schleiff 2008). Total salt affected area of the world is about 7\% (Musyimi et al. 2007) and it is mainly restricted to arid and semi-arid regions where land degradation and population growth are of major concern (Geissler et al. 2010). In Pakistan, nearly $10 \mathrm{M}$ ha areas are affected by different levels of salinity and it consists of $12.9 \%$ of total land in the country. The problem of salinity in the irrigated area of Pakistan occurred due to inadequate drainage practices (FAO 2008).

Seed germination plays important role towards yield (Sanchez et al. 2014). To start with the process of germination of seeds, absorption of water is the first step that should occur under favorable environmental conditions (Tobe et al. 2001). Salinity of growth medium delays or prevents seed germination and later on seedling establishment and such conditions prevail mainly due to evaporation of water under high temperature. Germination percentage and seed vigor index are the important criteria for selection of salt tolerant cultivars (Bybordi 2010).

Cluster bean (Cyamopsis tetragonoloba L.) also known as Guar is an important summer legume crop in Asian countries (Rao and Shahid 2011). It is mostly grown in the arid and semiarid regions and its uses are of multifarious nature as it is used for human consumption as well as forage for cattle (Satyavathi et al. 2014, Choy et al. 2015). Seeds of Guar contain Guar gum which is being used in wide range of industries such as textile, pharmaceutics, food industry, paint, and cosmetics (Mudgil et al. 2014, Jukanti et al. 2015). In view of the importance of cluster bean in the agrochemical industries and due to agrobotanical characters of this crop, this is gaining considerable attention to grow on abiotic stress hit areas (Ali et al. 2015). It is therefore, worthwhile to consider the problems caused by salinity in the production of this important crop and the main aim of the present study, was to examine the seed germinated and vigor indices under salinity stress.

*Author for correspondence: <abubakar@ciitvehari.edu.pk>. ${ }^{1}$ Department of Horticultural Sciences, Faculty of Agriculture and Environmental Sciences, The Islamia University of Bahawalpur, Pakistan. 


\section{Materials and Methods}

The seeds of cluster bean (Cyamopsis tetragonoloba L.) varieties (BR-90 and BR-2017) were collected from the Guar Research Station, Regional Agricultural Research Institute, Bahawalpur. The experiment was laid out in CRD with factorial arrangement. The study was conducted at the Department of Environmental Sciences, COMSATS University Islamabad, Vehari Campus. Thirty healthy seeds were placed in each Petri dish with filter paper Whatman No. 1 and salinity stress $(05,10,15,20 \mathrm{dS} / \mathrm{m})$ were imposed by preparing the solution of $\mathrm{NaCl}$ salt. Distilled water was used as control. Seed germination was counted daily by following the method of Association of Official Seed Analysis (AOSA 1990). Following parameters regarding germination were recorded: From the second day, the germinated seeds of clusterbean were counted daily at 10:00 a.m. and seeds having redicle length of $2 \mathrm{~mm}$ were considered germinated. Germinated seed counting continued till the germination became constant and the resulted final counting considered as final germination percentage. The germination percentage (GP) was calculated according to the formula of ISTA (2009).

$$
G P=\frac{N i}{N} \times 100
$$

where, $N i$ is the number of seeds germinated and $N$ is the total number of seeds.

Time taken for 50\% germination (T50) was calculated according to the following formula of Farooq et al (2005):

$$
T_{50}=t_{i}+\frac{\left[\frac{N}{2}-n_{i}\right](t j-t i)}{n_{l}-n_{i}}
$$

where, $N$ is the final number of seeds germinated and $n i$ and $n j$ are the cumulative numbers of seeds germinated at adjacent counts at times $t i$ and $t j$ when $n i<N / 2<n j$.

Mean germination time (MGT) was calculated according to the equation of Ellis and Roberts (1981):

$$
M G T=\frac{\Sigma D n}{\Sigma n}
$$

where, $n$ is the number of seeds germinated on day $D$ and $D i$ is the number of days as counted from the beginning of germination.

In order that, from the second day to 7 th day once in 24 hours germinated seeds were counted and germination index (GI) was determined following Maguire equation (1962):

Or

$$
\boldsymbol{G I}=\sum_{i=1}^{n} \frac{S i}{D i}
$$

$$
\mathrm{GI}=\left[\frac{\text { Number of germinated seeds in first count }}{\text { Days of first count }}\right]+\ldots+\left[\frac{\text { Number of germinated seeds in final count }}{\text { Days of final count }}\right]
$$

where, $G I$ is germination index (number of germinated seed in each day); $S i$ is number of germinated seeds in each numeration; $D i$ is number of days till nth numeration and $n$ is number of numeration times. (1984).

Germination stress index (GSI) is estimated by the formula of Bouslama and Schapaugh

$$
\mathrm{GSI}=\frac{\text { Germination speed at stress condition }(\mathrm{PIs})}{\text { Germination speed at control condition }(\mathrm{PIc})} \times 100
$$


Seed vigor index (SVI) was calculated with the help of Abdul-Baki and Anderson method (1970):

Seed vigor index $=\mathrm{GP} \times$ means of seedling length $\times 100$

where, $G P$ is germination percentage and seedling length is equal to radicle + plumule length. The radicle and plumule length were measured with the help of scale at the time of harvest.

Data were collected and analyzed statistically by using AVOVA and LSD test at 5\% level of probability and was used to test the differences among mean values (Steel et al. 1997).

\section{Results and Discussion}

The data presented in Fig. 1a showed that effect of different salinity treatments on germination percentage (GP) was non-significant $(\mathrm{p}>0.05)$ up to $100 \mathrm{mM}$. The higher levels of salinity (150 and $200 \mathrm{mM} \mathrm{NaCl}$ ) decreased the GP significantly. Maximum GP was recorded in control treatment while minimum at highest salinity level $(200 \mathrm{mM})$. Analyzed data indicated that germination percentage differ significantly in both the varieties (BR-90, BR-2017) of cluster bean at $200 \mathrm{mM}$ salinity. However, non-significant difference was recorded at all the lower salinity treatments. High concentration of $\mathrm{NaCl}$ salinity $(200 \mathrm{mM})$ led to a significant $(\mathrm{p}<0.05)$ reduction of germination percentage by 19 and 13 in BR-90 and BR-2017, respectively when compared with the control treatment. Increasing concentration of $\mathrm{NaCl}$ in the growth medium may decrease the water potential (Bradford 1995) and it may decrease or inhibit the seed water absorption that initiates the seed germination process (Katembe et al. 1998, Fatima et al. 2018). The reduction in the absorption of water due to increased level of salinity in the growth medium may be due to imbalance of anion and cation which creates ion toxicity (Panuccio et al. 2014).

The analyzed data (Fig. 1c) regarding time taken for 50\% germination (T50) was significantly $(\mathrm{p}<0.05)$ increased with increasing the salinity levels at all the treatments. However, the difference between the cultivars (BR-90 and BR-2017) at each salinity treatment was found to be non-significant ( $p$ > 0.05). The highest salinity level of $200 \mathrm{mM}$ increased the T50 value in BR-90 and BR-2017 by 57 and $58 \%$, respectively when compared with control treatment. Due to salinity stress, the water absorption rate of seed decreased leading delays in the metabolic activation necessary for the emission of the radicle and subsequent mobilization of reserves in different seed parts (Jamil et al. 2006).

Mean germination time (MGT) increased with the increase of salinity levels in both the cultivars (Fig. 1b). At control treatment the MGT significantly ( $\mathrm{p}<0.05$ ) decreased as compared to highest salinity level $(200 \mathrm{mM})$. Overall, non-significant difference of MGT was recorded at all salinity treatment levels for both BR-90 and BR-2017. High salinity treatment $(200 \mathrm{mM})$ of $\mathrm{NaCl}$ increased mean germination time in BR-90 and BR-2017 by 26 and 37\%, respectively when compared with control treatment (Fig. 1b). The results of present study correlate with those of Murillo-Amador et al. (2002) in cowpea and Okcu et al. (2005) in pea and they observed that $\mathrm{NaCl}$ delayed MGT. Similar results were reported by Mensah and Ihenyen (2009) that salinity stress delays the germination which may be due to reduction of absorption of water.

Fig. 1d showed that germination index (GI) decreased with the increase of salinity treatments. The difference between the cultivars (BR-90 and BR-2017) regarding GI was non-significant at all the salinity levels except at $100 \mathrm{mM}$ in which cultivar BR-90 attained the higher value of GI as compared to BR-2017. The highest concentration of $\mathrm{NaCl}(200 \mathrm{mM})$ led to a significant reduction of GI by 50 and $42 \%$ BR-90 and BR-2017, respectively when compared with the control treatment. It has been observed that value of GI is very helpful to predict the emergence of seed (Wang et al. 2004) and it decreased under stress. 
Germination stress index (GSI) decreased gradually with the increase in salinity levels. The highest GSI in both the cultivars (BR-90 and BR-2017) was observed at control treatment and the lowest was recorded at $200 \mathrm{mM}$ salinity level. However, non-significant difference of GSI value was recorded in both BR-90 and BR-2017 at all salinity levels. Both the cultivars (BR-90 and BR2017) showed the same gradual change in GSI by increasing the salinity treatment. High concentration of $\mathrm{NaCl}$ salinity reduces the GSI in BR-90 and BR-2017 by 36 and 44\%, respectively when compared with control treatment. Germination stress index (GSI) had a significant positive correlation with the speed of germination and cultivars attaining higher value of GSI which can tolerate the stress conditions (Sapara 1991, Bahari and Bighdilu 2014).
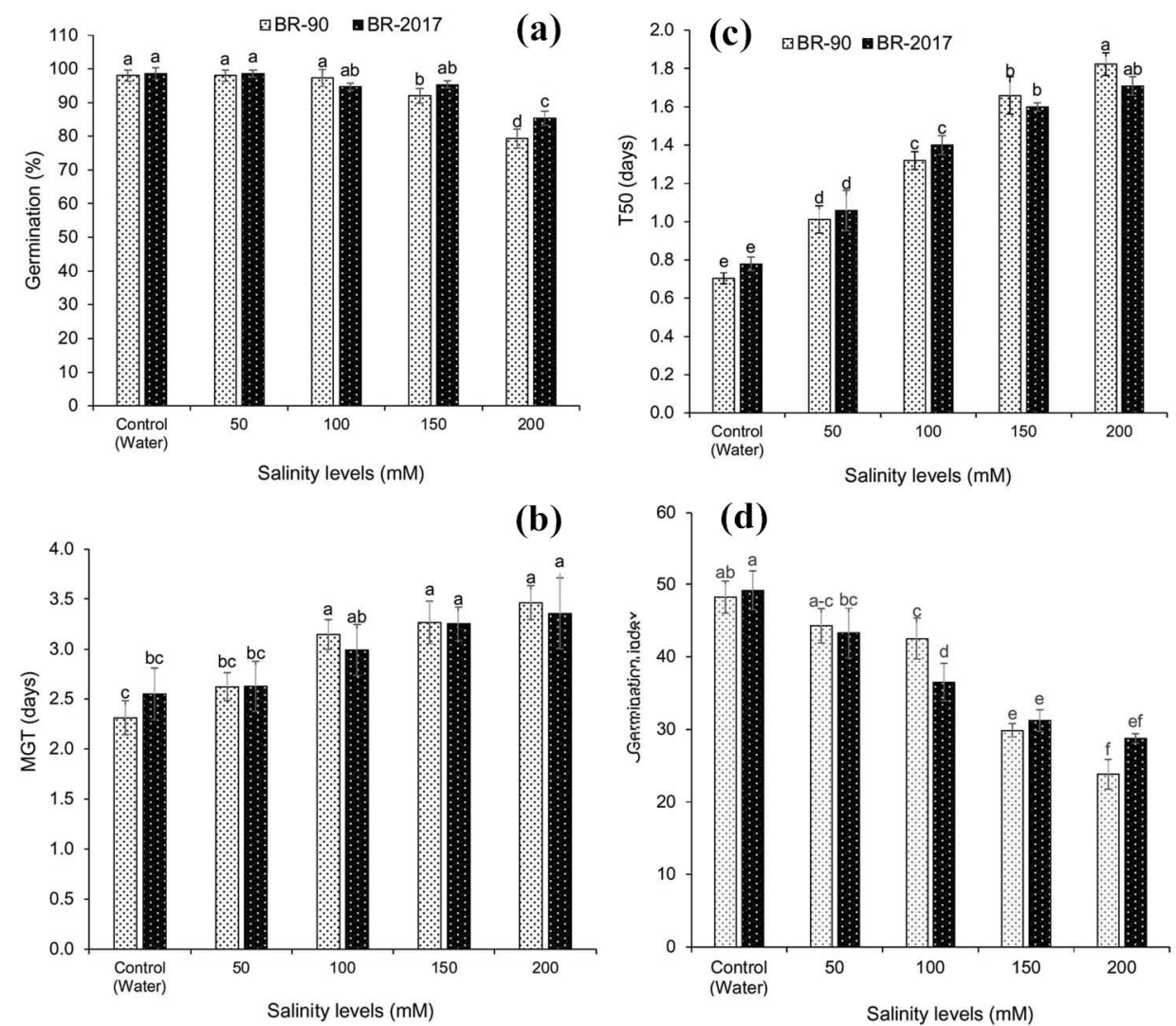

Fig. 1. Germination percentage (a), mean germination time (b), time taken for $50 \%$ germination (c) and germination index (d) of cluster bean seed sown under salinity levels. Values are mean \pm standard error.

Seed vigor index (SVI) decreased significantly $(\mathrm{p}<0.05)$ with the increase at all salinity levels. Data presented in Fig. 2a, showed that the highest SVI was observed at control treatment and it sharply decreased to minimum at the highest salinity level $(200 \mathrm{mM})$ in both cultivars (BR90 and BR-2017). The non-significant difference of SVI value was observed between BR-90 and BR-2017 at all the salinity treatments except in control where BR-90 attained the higher value as compared to BR-2017. Increase in concentration of $\mathrm{NaCl}$ salinity reduces the SVI in BR-90 and BR-2017 by 82 and $83 \%$, respectively as against control treatment. Germination and seedling 
growth indices e.g. seed vigor are the most important criteria for selection of tolerant cultivars (Bybordi 2010) and salinity stress influences the seed vigour during germination of soybean seed (Khajeh-Hosseini et al. 2003).

According to the results presented Fig. 2c the radical length of cluster bean seedling gradually deceased by the increase of $\mathrm{NaCl}$ salt treatment in the growth medium as compared to control. Maximum radical length was observed at control level and minimum at $200 \mathrm{mM}$ salinity. However, non-significant difference of radicle length was recorded both in BR-90 and BR-2017. The highest salinity level $(200 \mathrm{mM})$ reduces the redicle length in BR-90 and BR-2017 by 78 and $75 \%$, respectively when compared with control treatment.
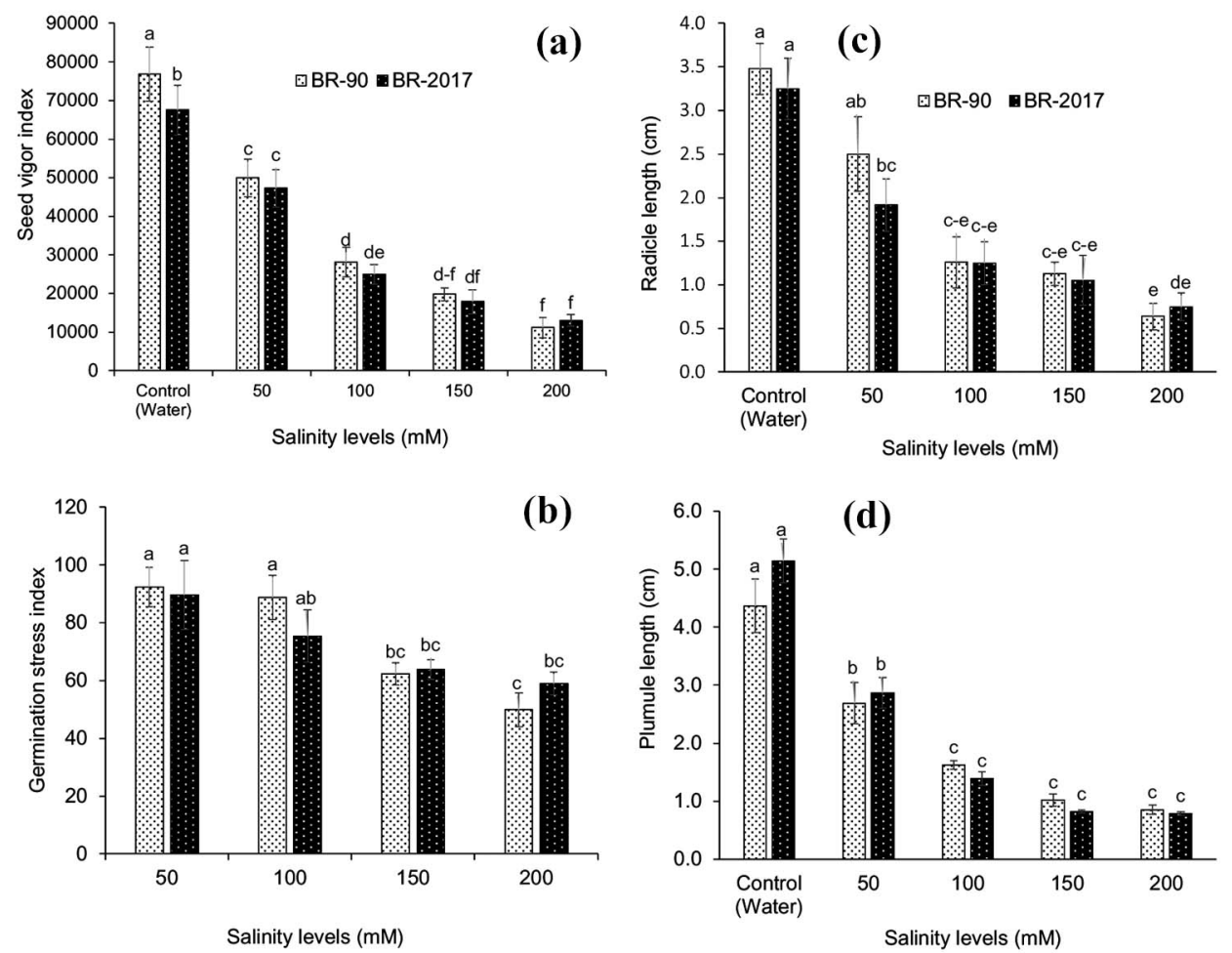

Fig. 2. Seed vigor index (a), germination stress index (b), radicle length (c) and plumule length (d) of cluster bean seed sown under salinity levels. Values are mean \pm standard error.

Plumule length decreased with increasing salinity level in the growth medium. Plumule length decreased sharply up to $100 \mathrm{mM}$ salinity treatment and then non-significant decrease was observed. High $\mathrm{NaCl}$ concentration $(200 \mathrm{mM})$ reduces the plumule length of plants of BR-90 and BR-2017 by 84 and $82 \%$, respectively when compared with control treatment (Fig. 2d). These results are in agreement Soltani et al. (2002) and Esechie et al. (2002) that root and shoot lengths were diminished by increasing the salinity stress in the growth medium. Eeffects of salinity stress on maize crop indicates that there is considerable variation among root and shoot length of cultivars. Furthermore, it was found that those having high root and shoot length result in high biomass and are considered salt tolerant (Akram et al. 2007, Akram et al. 2010). 
Correlation analysis indicated that highly significant $\left(\mathrm{p}<0.05,0.98^{* *}\right)$ correlation was observed between T50 and MGT. It was also observed that SVI and GI have also highly significant relationship $\left(\mathrm{p}<0.05,0.92^{* *}\right)$. However, highly negative correlation was observed between GI with T50 and MGT. Highly negative correlation was also observed for SVI with MGT, T50 and GI (Table 1).

Table 1. Pearson correlation coefficient (r) for analyzed variables.

\begin{tabular}{llllll}
\hline Parameters & GP & MGT & T50 & GI & SVI \\
\hline GP & 1.00 & - & - & - & - \\
MGT & $-0.76^{*}$ & 1.00 & - & - & - \\
T50 & $-0.79^{*}$ & $0.98^{* *}$ & 1.00 & - & - \\
GI & $0.86^{* *}$ & $-0.92^{* *}$ & $-0.97 * *$ & 1.00 & - \\
SVI & $0.70^{\mathrm{NS}}$ & $-0.97^{* *}$ & $-0.98^{* *}$ & $0.92^{* *}$ & 1.00 \\
\hline
\end{tabular}

*** Significant at $\mathrm{p}<0.05$ and $0.01 \%$ levels, respectively. GP $=$ Germination percentage, MGT $=$ Mean germination time, T50 = Time taken for 50\% germination, GI $=$ Germination index and SVI $=$ Seed vigor index.

In conclusion, it may be said that high salinity remarkably inhibited the seed germination, decreased the germination indices and also delayed the germination time in cluster bean. It is evident that $50-200 \mathrm{mM} \mathrm{NaCl}$ salinity significantly reduced the radicle and plumule length of cluster bean seedling.

\section{References}

Abdul-Baki AA and Anderson JD 1970. Viability and leaching of sugars from germinating barley. Crop Sci. 10: 31-34.

Akram M, Malik MA, Ashraf MY, Saleem MF and Hussain M 2007. Competitive seedling growth and $\mathrm{K}^{+} / \mathrm{Na}^{+}$ratio in different maize (Zea mays L.) hybrids under salinity stress. Pak. J. Bot. 39(7): 2553-63.

Akram M, Ashraf MY, Ahmad R, Waraich EA, Iqbal J and Mohsan M 2010. Screening for salt tolerance in maize (Zea mays L.) hybrids at an early seedling stage. Pak. J. Bot. 42(1): 141-54.

Ali Z, Ashraf M, Al-Qurainy F, Khan S and Akram NA 2015. Field screening of Guar (Cyamopsis tetragonoloba (L.) Taub.] accessions for enhanced forage production on hot drylands. Pak. J. Bot. 47: 1429-1437.

AOSA 1990. Rules for testing seeds. J. Seed Technol. 12: 1-112.

Bahari N and Bighdilu BB 2014. Evaluation of germination stress indicators and germination speed at stress canola genotypes. Indian J. Fundamental and Applied Life Sci. 4(1): 222-225.

Bouslama M and Schapaugh WT 1984. Stress tolerance in soybean. Part 1: evaluation of three screening techniques for heat and drought tolerance. Crop Sci. 24: 933-937.

Bradford JK 1995. Water relations in seed germination. In: Kigel J, Galili G, (eds.). Seed Development and Germination. Marcel Dekker Inc., New York. pp. 351-396.

Bybordi A 2010. The Influence of salt stress on seed germination, growth and yield of canola cultivars. Notulae Botanicae Hortic. Agrobotanici. Cluj-Napoca 38:128-133.

Choy SY, Prasad KMN, Wu TY and Ramanan RN 2015. A review on common vegetables and legumes as promising plant-based natural coagulants in water clarification. Int. J. Environ. Sci. Technol. 12(1): 367390.

Ellis RA and Roberts EH 1981. The quantification of ageing and survival in orthodox seeds. Seed Sci. Technol. 9: 373-409. 
Esechie HA, Al-Saidi A and Al-Khanjari S 2002. Effect of sodium chloride salinity on seedling emergence in chickpea. J. Agron. Crop Sci. 188(3): 155-160.

FAO. 2008. FAO Land and Plant Nutrition Management Service. Available online: http://www.fao.org/ag/ agl/agll/spush [Accessed 25/04/2008].

Farooq M, Basra SMA, Hafeez K and Ahmad N 2005. Thermal hardening: A new seed vigor enhancement tool in rice. J. Integrated Plant Biol. 47: 187-93.

Fatima N, Akram M, Shahid M, Abbas G, Hussain M, Nafees M, Wasaya A, Tahir M and Amjad M 2018. Germination, growth, and ions uptake of moringa (Moringa oleifera L.) grown under saline condition. J. Plant Nutrit. DOI: 10.1080/01904167.2018.1459690

Geissler N, Hussin S and Koyro HW 2010. Elevated atmospheric $\mathrm{CO}_{2}$ concentration enhances salinity tolerance in Aster tripolium L. Planta 231: 583-594.

ISTA. 2009. Handbook of Seedling Evaluation, 3rd Ed. ISTA Germination Committee, Zurich, Switzerland. 520.

Jamil M, Lee DB, Bae LD, Yong JK, Ashraf M, Chun LS and Shik RE 2006. Effect of salt (NaCl) stress on germination and early seedling growth of four vegetables species. J. Central European Agric. 7: 273282.

Jukanti A, Bhatt R, Sharma R and Kalia R 2015. Morphological, agronomic, and yield characterization of cluster bean (Cyamopsis tetragonoloba L.) germplasm accessions. J. Crop Sci. Biotechnol. 18: 83-88.

Katembe WJ, Ungar AI and Mitchell JP 1998. Effect of salinity on germination and seedling growth of two Atriplex species (Chenopodiaceae). Annals of Bot. 82: 167-175.

Khajeh-Hosseini M, Powell AA and Bingham IJ 2003. The interaction between salinity stress and seed vigour during germination of soybean seeds. Seed Sci. Technol. 31(3): 715-725.

Maguire JD 1962. Speed of germination aid in selection and evaluation for seedling emergence and vigor. Crop Sci. 2: 176-177.

Mensah J K and Ihenyen J 2009. Effects of salinity on germination, seedling establishment and yield of three genotypes of mung bean (Vigna mungo L.) in Edo State, Nigeria. Nigerian Annals of Natural Sci. 8(2): 17-24.

Mudgil D, Barak S and Khatkar BS 2014. Guar gum: Processing, properties and food applications - A Review. J. Food Sci. Technol. 51(3): 409-418.

Murillo-Amador B, Lopez-Aguilar R, Kaya C, Larrinaga-Mayoral J and Flores-Hernandez A 2002. Comparative effects of $\mathrm{NaCl}$ and polyethylene glycol on germination, emergence and seedling growth of cowpea. J. Agron. Crop Sci. 188(4): 235-247.

Musyimi DM, Netondo GW and Ouma G 2007. Effects of salinity on growth and photosynthesis of avocado seedling. Int. J. Bot. 3: 78-84.

Okcu G, Kaya MD and Atak M 2005. Effects of salt and drought stresses on germination and seedling growth of pea (Pisum sativum L.). Turk. J. Agric. Forest. 29(4): 237-242.

Panuccio M R, Jacobsen SE, Akhtar SS and Muscolo A 2014. Effect of saline water on seed germination and early seedling growth of the halophyte quinoa. AoB Plants 6: plu 047, doi:10.1093/aobpla/plu047.

Rao NK and Shahid M 2011. Potential of cowpea (Vigna unguiculata L.) and guar (Cyamopsis tetragonoloba L.) as alternative forage legumes for the United Arab Emirates. Emirates J. Food and Agric. 23(2): 147-156.

Sapara VT, Sarage E, Anaele AO and Beyl CA 1991. Varieties differences of wheat and triticale to water stress. J. Agron. Crop Sci. 167: 23-28.

Sanchez PL, Chen MK, Pessarakli M, Hill HJ, Gore MA and Jenks MA 2014. Effects of temperature and salinity on germination of non-pelleted and pelleted Guayule (Parthenium argentatum A. Gray) seeds. Industrial Crops and Products 55: 90-96.

Satyavathi P, Vanaja M, Reddy AGK, Vagheera P, Reddy AN, Kumar GV, Razak A, Vaidya S, Sowmya P and Khan I 2014. Identification of suitable guar genotypes for summer season of semi-arid region. Int. J. Applied Biol. Pharmaceutical Technol. 5(4): 71-73. 
Schleiff U 2008. Analysis of water supply of plants under saline soil conditions and conclusions for research on crop salt tolerance. J. Agron. Crop Sci. 194: 1-8.

Soltani A, Galeshi S, Zeinali E and Latifi N 2002. Germination, seed reserve utilization and seedling growth of chickpea as affected by salinity and seed size. Seed Sci. Technol. 30(1): 51-60.

Steel RGD, Torrie J H and Dickey DA 1997. Principles and Procedure of Statistics. McGrow Hill book Co., USA. 178-18.

Tobe K, Zhang L, Qiu GY, Shimizu H and Omasa K 2001. Characteristics of seed germination in five nonhalophytic chinese desert shrub species. J. Arid. Environ. 47: 191-201.

Wang YR, Yu L, Nan ZB and Liu YL 2004. Vigor tests used to rank seed lot quality and predict field emergence in four forage species. Crop Sci. 44(2): 535-541.

(Manuscript received on 29 May, 2018; revised on 18 December, 2019) 